\title{
BMJ Open Misconceptions about COVID-19 among older Rohingya (forcefully displaced Myanmar nationals) adults in Bangladesh: findings from a cross- sectional study
}

\author{
Sabuj Kanti Mistry (D) , ${ }^{1}$ A R M Mehrab Ali (D) , ${ }^{1}$ Uday Narayan Yadav (D) , ${ }^{2}$ \\ Saruna Ghimire, ${ }^{3}$ Md. Belal Hossain (1) , ${ }^{4}$ Manika Saha, ${ }^{5}$ Sompa Reza, ${ }^{6}$ \\ Progati Bakshi, ${ }^{7}$ Abu Toha M R H Bhuiyan, ${ }^{8}$ Mark Harris (1) ${ }^{2}$
}

To cite: Mistry SK, Ali ARMM, Yadav UN, et al. Misconceptions about COVID-19 among older Rohingya (forcefully displaced Myanmar nationals) adults in Bangladesh: findings from a cross-sectional study. BMJ Open 2021;11:e050427. doi:10.1136/ bmjopen-2021-050427

- Prepublication history and additional supplemental material for this paper are available online. To view these files, please visit the journal online (http://dx.doi.org/10.1136/ bmjopen-2021-050427)

Received 22 February 2021 Accepted 11 May 2021

Check for updates

(C) Author(s) (or their employer(s)) 2021. Re-use permitted under CC BY-NC. No commercial re-use. See rights and permissions. Published by BMJ.

For numbered affiliations see end of article.

Correspondence to

Sabuj Kanti Mistry;

smitra411@gmail.com

\section{ABSTRACT}

Objectives Due to low health literacy and adverse situation in the camps, there are possibilities of misconceptions related to COVID-19 among the older Rohingya (forcefully displaced Myanmar nationals or FDMNs) adults in Bangladesh. The present research aimed to assess the level of misconceptions and the factors associated with it among the older FDMNs in Bangladesh. Design Cross-sectional.

Setting A selected Rohingya camp situated in Cox's Bazar, a southeastern district of Bangladesh.

Participants Information was collected from 416 conveniently selected FDMNs who were aged 60 years and above.

Primary and secondary outcome measures The primary outcome was misconceptions related to the spread, prevention and treatment of COVID-19. Information on 14 different locally relevant misconceptions was gathered, each was scored as one, and obtained a cumulative score, ranging from 0 to 14 , with a higher score indicating a higher level of misconceptions. A multiple linear regression model explored the factors associated with misconceptions.

Results The participants had an average of five misconceptions. The most prevalent misconceptions were: everyone should wear personal protective equipment when outside (84.6\%) and its prevention by nutritious food $(62.5 \%)$ and drinking water (59.3\%). Other notable misconceptions included the spread of COVID-19 through mosquito bites (42\%) and its transmissions only to the non/less religious person (31.4\%). In regression analyses, memory or concentration problems, communication frequency with social networks, pre-existing conditions and receiving information from health workers were significantly associated with higher COVID-19 misconceptions. These misconceptions were less likely among those overwhelmed by COVID-19, having COVID-19 diagnosed friends or family members and receiving information from friends and family.

Conclusions Overall, we found that misconceptions were prevalent among the older FDMNs in Bangladesh. The associations have important implications for programmes
Strengths and limitations of this study

- The study was conducted among the Rohingya (forcibly displaced Myanmar nationals or FDMNs) older adults in Bangladesh, who are vulnerable to having misconceptions related to COVID-19.

- As we conveniently selected the participants from the selected Rohingya camp, there is possibilities of selection bias.

- The study was carried out in a single camp that limits the generalisability of the findings for the entire camp population.

- Since the study was cross-sectional in nature, no temporal relationship is possible.

- The findings are self-reported and relied on participants recall; therefore, recall bias is possible.

to prevent and manage COVID-19 in these settings. Health workers need to be adequately trained to provide clear communication and counter misconceptions.

\section{BACKGROUND}

As of 8 February 2021, the ongoing COVID-19 pandemic has claimed over 2.3 million lives globally and added over 100 million confirmed cases to the global burden of disease. ${ }^{1}$ By the same date, Bangladesh reported over 538 thousand COVID-19 confirmed cases and 8205 COVID-19 deaths. ${ }^{1}$ Although the knowledge of different aspects of COVID-19 is still emerging, the available evidence consistently shows the disproportional impact of COVID-19, making one subpopulation more vulnerable than others. ${ }^{23}$ One such vulnerable population is older adults, who are at increased risk of mortality, severe illness and often require hospitalisation and intensive care for COVID-19. ${ }^{4}$ Notably, 8 out of 10 
COVID-19 deaths in the USA have been reported among adults aged 65 years and older. ${ }^{5}$

COVID-19 has reminded us how interconnected the world is, and it impacts everyone-people on both sides of the borders as well as the refugees and other displaced people. Refugees and displaced people are at the greatest risk of COVID-19 because, on the one hand, they live in densely populated camps that lack basic sanitation, which makes social distancing and hand washing or maintaining personal hygiene difficult. ${ }^{6}$ On the other hand, their access to health services may be limited, which may preclude them from the diagnostics and clinical management in the events of an outbreak. ${ }^{7}$

The Rohingyas (forcefully displaced Myanmar nationals or FDMNs) are mostly Muslim minority resident of Myanmar's Rakhine State who faced decades of systematic discrimination, statelessness and targeted violence by Myanmar's military that forced them to flee the Rakhine state and seek refuge in several Asian countries but mostly in neighbouring Bangladesh. ${ }^{89}$ Although there have been ongoing discriminations and violent attacks, the spikes in violence and subsequent mass displacements in 1978, 1991-1992, 2016 and again in 2017 drew international attention. ${ }^{1011}$ The FDMNs influx into Bangladesh in 2017 is considered the largest and fastest of these movements and involved about a million Rohingya, joining nearly 300000 people who had previously fled Myanmar. ${ }^{12}$ They live in refugee camps in Cox's Bazar, a southeastern district of Bangladesh, about $280 \mathrm{~km}$ away from Rakhine state of Myanmar (the place from where they were displaced), which is now the world's largest camp for displaced people. ${ }^{13} 14$ The United Nations Refugee Agency indicates more than 31500 FDMNs in the camps to be aged 60 years and older. ${ }^{15}$

A previous study demonstrated that people in Rohingya camps are at increased risk of COVID-19. ${ }^{16}$ High population density (40000 people per square kilometre) and poor sanitation facilitate the spread of COVID-19 in the Rohingya camps. ${ }^{14}$ More than half of the Rohingya population faces water supply shortages, and $>30 \%$ of the households do not have access to soap. ${ }^{17}$ While data specifically on older Rohingya is unavailable, recent evidence suggests a high prevalence of non-communicable diseases (NCDs), particularly hypertension (51.5\%) and diabetes $(14.2 \%),{ }^{18-20}$ among the Rohingya adults, which increases their risk of COVID-19 related complications. Furthermore, the real burden of NCDs among Rohingya could be illustrated by the 'iceberg phenomenon' of disease whereby inadequate screening and diagnosis of NCDs in Rohingya camps may have underestimated the actual burden. ${ }^{14}$

The role of nutrition in inferring immunity is undebatable. Food insecurity and malnutrition are common among $\mathrm{FDMNs}^{21}$ and could further increase their susceptibility to infections. These factors, coupled with the biological senescence, make Rohingya older adults a highly at-risk group for COVID-19. As of 2 February 2021, a total of 5886 COVID-19 positive cases have been confirmed in the Cox's Bazar district, of which 381 are in the Rohingya camps, and the numbers are rapidly increasing. ${ }^{22}$ However, health professionals consider the number of known cases to be low because factors such as the fear of deportation, isolation in quarantines and separation from their families preclude FDMNs from taking testing voluntarily. ${ }^{23}$

During this pandemic, public health professionals are not just fighting the pandemic but also the array of COVID-19 misinformation that has spread globally. Top officials from the United Nations and the WHO have warned against the 'pandemic of misinformation' or 'infodemic'. Specifically, among refugee and displaced populations, the misinformation, disinformation, myths and misconceptions are likely to flourish because of lower literacy and limited access to reliable sources of information such as health services or health professionals. ${ }^{24} 25$ In September 2019, Bangladeshi authorities cut-off access to telecommunications and the internet in the camps, thus barring the residents from accessing information and facilitating to flourish fear, misinformation, stigma and stereotypes about COVID-19 in the camps. ${ }^{26}$ Later, although the services were restored, they were poorly accessible and rarely used by older adults. Furthermore, among Rohingya, social and religious taboos, and orthodox thinking, which is more common among older members, can contribute to misconceptions. When interviewed by Amnesty International in April 2020, most older people reported that they had received little specific information about COVID-19. ${ }^{27}$

In the Bangladeshi population and more specifically among FDMNs, it is a big challenge to clarify and address myths and misconceptions. ${ }^{28}$ Identifying and demystifying prevalent misconceptions is crucial, especially during a pandemic, as accurate public health information can help prevent infection and promote health measures. The level of misconceptions related to COVID-19 has not been well described among the FDMNs, particularly among the older adults who are the most vulnerable. Therefore, the present study aimed to assess misconceptions and their correlates among the older FDMNs in Bangladesh.

\section{METHODS}

\section{Study design and participants}

The study followed a cross-sectional design and was conducted by Aureolin Research, Consultancy and Expertise Development Foundation among the FDMNs from the Rohingya camps situated in the Cox's Bazar district in the southeastern part of Bangladesh in October 2020.

The sample size of 460 was calculated with the following assumptions: (unknown) prevalence of COVID-19 related misconceptions $=50 \%$, sampling error $=5 \%, \mathrm{CI}=95 \%$ and non-response rate $=20 \%$. Of the 457 eligible participants approached, a total of 416 Rohingya older adults responded to the study (response rate $91 \%$ ). There is a total of 34 Rohingya camps located in Cox's Bazar district from which Camp 08E (SSID CXB-210), located at Ukhia 


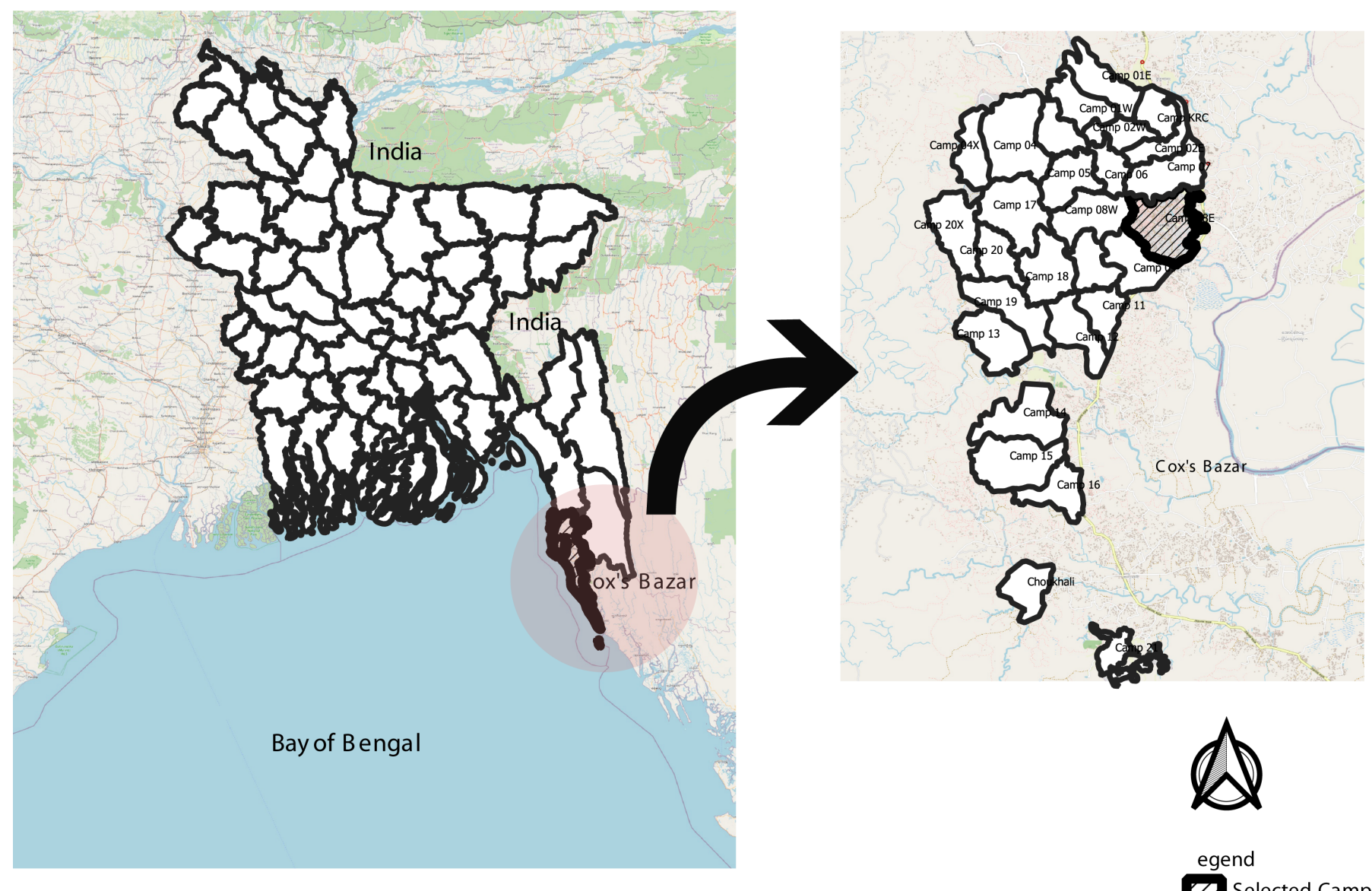

Figure 1 Geographical location of the study area (source: Site Management Sector, Office of the Refugee Relief \& Repatriation Commissioner, Inter Sectoral Coordination Group). Retrieved from https://data.humdata.org/dataset/1a67eb3b-57d8-4062b562-049ad62a85fd?fbclid=IwARON_GqOqP7FwcoGMUEiZu4Sj5uOPRrD86cPHOmqfy9O3oGzCCoCki9ItY.

subdistrict, was conveniently selected (figure 1). In the absence of the list of the older adults in Rohingya camps, a convenient sampling technique was used to identify the eligible participants in the selected camp. The surveyors continued visiting the households until the desired sample size was achieved. If the approached household did not have an eligible participant, the surveyors moved to the next one, and if the household had more than one older adults, all of them were interviewed. The inclusion criteria included age $\geq 60$ years and FDMN status. The exclusion criteria included adverse mental conditions (clinically proved schizophrenia, bipolar mood disorder and dementia/cognitive impairment), a hearing disability or unable to communicate.

\section{Measures}

\section{Outcome measure}

The primary outcome of the study was the level of misconceptions related to COVID-19. WHO has compiled a list of the most common COVID-19 'MythBusters'. ${ }^{29}$ Our survey included locally relevant misconceptions, such as transmission through mosquitoes' bites, transmitted only to people who practice 'socially unacceptable activities', and so forth. We also included items from an African study that shed light on additional misconceptions such as antibiotics being effective for treatment and homemade remedies to cure COVID-19. We prepared a list of 14 different misconceptions, related to the spread, prevention and treatment of COVID-19. Each item on misconceptions was assessed as a true/false statement. Each misconception scored one, and the correct responses were assigned 0 . The cumulative score of the 14 -items ranged from 0 to 14 , with a higher score indicating a higher level of misconceptions.

\section{Explanatory variables}

Explanatory variables considered in this study were age (categorised as 60-69, 70-79 and $\geq 80$ years), sex (male/female), marital status (currently married/ single), literacy (yes $/$ no), family size $(\leq 4$ and $>4$ ), living arrangements (living with other family members/ living alone), dependence on family for a living (yes/ no), source of COVID-19 related information (radio/ television, health workers and friends/family/neighbours), walking distance from nearest health centre $(<30 \mathrm{~min} / \geq 30 \mathrm{~min})$, memory or concentration problem (no problem/low memory or concentration), feeling concerned about COVID-19 (hardly and sometimes/ often) feeling overwhelmed because of COVID-19 (hardly and sometimes/often), presence of any NCDs 
(yes/no), frequency of communication with others during COVID-19 (less than previous/same as previous) and COVID-19 diagnosis among close friends or family members (yes/no).

Information on pre-existing conditions such as arthritis, hypertension, heart diseases, stroke, hypercholesterolaemia, diabetes, chronic respiratory diseases, chronic kidney disease and cancer were collected by selfreported. This information was verified with available health records if available and/or with family members. We did not collect information on the income and occupation as the refugee population is mostly unemployed and dependent on aid funding.

\section{Data collection tools and techniques}

A pretested semistructured questionnaire in the Bengali language was used to collect the information through faceto-face interviews while adhering to COVID-19 related health safety measures. Data were electronically recorded in SurveyCTO mobile app (https:/ /www.surveycto.com/) by eight research assistants, who were local residents of Cox's Bazar, fluent in Rohingya dialects and had previous experience of administering health survey on an electronic platform. The research assistants were trained extensively before the data collection through the Zoom meeting.

Two team members first translated the original English version of the questionnaire into Bengali language and then back-translated to English to ensure the contents' consistency. The Bengali version of the tool was piloted among a small sample $(\mathrm{n}=10)$ of Rohingya older adults from the selected camp to refine the language in the final version. The pretest samples were not included in the final study.

\section{Statistical analyses}

The distribution of the variables was assessed through descriptive statistics. To explore the factors associated with misconceptions among the participants, we used the multiple linear regression model. The previously described cumulative misconception score, range 0-14, was the outcome variable for regression analyses, and we used the backward elimination criteria with Akaike information criterion (AIC) to select the final model. Adjusted beta-coefficient $(\beta)$ and $95 \% \mathrm{CI}$ are reported in the main table, and the model diagnostics results, such as normality of the residuals and multicollinearity, are reported in online supplemental files 12. All analyses were performed using the statistical software package Stata (V.14.0).

\section{Patient and public involvement in research}

Neither patients nor the public were involved in the design or conduct of this study. Participants also did not contribute to the writing or editing of this manuscript. Informed written consent was sought from each participant before the interview.

\section{RESULTS}

\section{Participants' characteristics}

As summarised in table 1, of the total 416 older Rohingya FDMNs aged 60 years and above, the majority were in their $60 \mathrm{~s}(74 \%)$, male $(60.3 \%)$, married $(93.5 \%)$, illiterate $(97.6 \%)$ and coresided with other family members $(87.0 \%)$. Over half $(54.1 \%)$ of the participants reported dependency on family members for living, and most $(79.3 \%)$ resided within $30 \mathrm{~min}$ walking distance from the nearest health facility. The most common sources of COVID-19 related information among the participants were health workers $(72.2 \%)$ and friends/family/neighbours $(64.7 \%)$. Half reported feeling overwhelmed due to the pandemic, and two in five were concerned about it. Social interactions were reduced as 59\% reporting less frequent communication with others during the pandemic. One in ten (12\%) reported COVID-19 diagnosis in close friends or relatives.

\section{Prevalence of COVID-19 misconceptions}

Participants' misconceptions related to the spread, prevention and treatment of COVID-19 are presented in table 2. On average, participants had misconceptions about five items (mean misconception score $=4.6$ and range 0-11). The most prevalent misconceptions were those related to the prevention of COVID-19 and included misconceptions about wearing personal protective equipment (PPE) when outdoors $(84.6 \%)$ and its prevention by nutritious food $(62.5 \%)$ and drinking water $(59.3 \%)$. Four in 10 participants believed that COVID-19 spreads through mosquito bites (42\%). Other notable misconceptions included participants' belief that COVID-19 transmits only to non/less-religious people $(31.4 \%)$ and those who conduct socially unacceptable activities $(25.7 \%)$. Although one-fifth of the participants had misconceptions that doctors could cure COVID-19, relatively, participants were accurately informed that it could not be cured by antibiotics and traditional healers (table 2).

\section{Factors associated with COVID-19 misconceptions}

The full model included the demographic and lifestyle characteristics and COVID-19 related variables (table 1) deemed to be associated with misconceptions. The final model, based on the lowest AIC, retained the variables shown in table 3 . Hence, the model is adjusted for all the variables in table 3 . In the adjusted model, memory/ concentration problems, pre-existing conditions, information sources for COVID-19, overwhelmed by COVID-19, frequency of communication and COVID-19 diagnosis of close friends or family members were significantly associated with COVID-19 misconceptions among study participants (table 3). Average misconception scores were 0.88 units higher among participants reporting low memory or concentration problems than those with no such problems $(\beta: 0.88,95 \%$ CI 0.31 to 1.44$)$. Similarly, the misconception scores were 5.88 units higher among those with pre-existing chronic conditions $(\beta: 5.88,95 \%$ CI 2.68 to 
Table 1 Characteristics of the participants $(n=416)$

\begin{tabular}{lrr} 
Characteristics & N & \multicolumn{1}{c}{$\%$} \\
\hline Age (year) & & \\
$60-69$ & 308 & 74.0 \\
$70-79$ & 83 & 20.0 \\
$\geq 80$ & 25 & 6.0 \\
Sex & & \\
$\quad$ Male & 251 & 60.3 \\
Female & 165 & 39.7 \\
Marital status & & \\
$\quad$ Married & 389 & 93.5 \\
$\quad$ Single & 27 & 6.5 \\
Literacy & & \\
$\quad$ Illiterate & & 97.6 \\
literate & 406 & 2.4
\end{tabular}

Family size

$\begin{array}{lrr}\text { 0-4 } & 167 & 40.1 \\ >4 & 249 & 59.9 \\ \text { Living arrangement } & & \\ \text { Living with family members } & 362 & 87.0 \\ \text { Living alone } & 54 & 13.0\end{array}$

Dependent on the family for living

$\begin{array}{ccc}\text { No } & 191 & 45.9 \\ \text { Yes } & 225 & 54.1 \\ \text { Walking distance to the nearest health centre } & \\ \text { <30 min } & 330 & 79.3 \\ \geq 30 \text { min } & 86 & 20.7\end{array}$

Memory or concentration problems

\begin{tabular}{lrl} 
No problem & 356 & 85.6 \\
Low memory or concentration & 60 & 14.4 \\
\hline Pre-existing chronic conditions & & \\
No & 295 & 70.9 \\
Yes & 121 & 29.1
\end{tabular}

*Sources of COVID-19 related information

\begin{tabular}{|lll}
\hline Radio/television & 178 & 42.8 \\
\hline Health workers & 298 & 72.2 \\
\hline $\begin{array}{l}\text { Friends/family/neighbours } \\
\text { Concerned about COVID-19 }\end{array}$ & 267 & 64.7 \\
\hline $\begin{array}{l}\text { Hardly } \\
\text { Sometimes/often }\end{array}$ & 256 & 61.5 \\
\hline $\begin{array}{l}\text { Overwhelmed by COVID-19 } \\
\text { Hardly }\end{array}$ & 160 & 38.5 \\
\hline Sometimes/often & 243 & 49.1 \\
\hline
\end{tabular}

Feeling left out during the pandemic

$\begin{array}{lll}\text { Hardly } & 274 & 65.9 \\ \text { Sometimes/often } & 142 & 34.1\end{array}$

Frequency of communication during COVID-19
Table 1 Continued

\begin{tabular}{lcl}
\hline Characteristics & N & $\%$ \\
\hline Same as previous & 170 & 40.9 \\
Less than previous & 246 & 59.1 \\
Close friends or family members diagnosed with COVID-19 \\
No & 367 & 87.9 \\
Yes & 49 & 12.1 \\
\hline
\end{tabular}

${ }^{*}$ Multiple responses so total percentage may not equal 100.

12.93), 0.53 units higher among those receiving COVID-19 information from health workers $(\beta: 0.53,95 \%$ CI 0.01 to 1.04 ) and 3.19 units higher among the participants who less frequently communicated with friends and relatives during the pandemic ( $\beta: 3.19,95 \%$ CI 2.67 to 3.70). However, the misconception scores were 1.03 units lower among participants receiving COVID-19 related information from their friends, family and neighbours $(\beta:-1.03$, $95 \%$ CI -1.55 to -0.52 ) compared with those who did not, 0.96 units lower among participants overwhelmed by the pandemic $(\beta:-0.96,95 \% \mathrm{CI}-1.46$ to -0.46$)$ and 2.33 units lower among participants who had close friends or family members diagnosed with COVID-19 $(\beta$ : $-2.33,95 \%$ CI -3.43 to -1.22 ).

\section{DISCUSSION}

This study assessed the misconceptions about the spread, prevalence and treatment of COVID-19 among older Rohingya FDMNs in Bangladesh and found many prevalent misconceptions. One apparent reason for the prevailing misconceptions about COVID-19 among study participants could simply be due to low literacy; 98\% of participants were illiterate. The Rohingya people in Bangladesh have been traumatised by systemic violence and persecution in Myanmar, and they live in crowded camps with limited access to resources, technologies and information, which may facilitate the spread of incorrect information about COVID-19 in the camps, leading to misconceptions. ${ }^{1416}$

Although prior studies have not focused on refugee and displaced populations, studies among general adults suggest that various misconceptions are very likely to persist during pandemic. ${ }^{30} 31$ In line with our findings, previous studies have also documented misconceptions about spread through mosquitoes, prevention through nutrition, drinking water and the use of antibiotics, and severe outcomes among smokers. ${ }^{32-34}$ Although the role of a healthy diet and hydration in promoting health and well-being is indisputable, there is no evidence that it directly prevents COVID-19. Among the refugee population where scarcity of safe water and nutritious food is paramount, their perceptions about these commodities' positive effects are understandable. Likewise, the deleterious impact of smoking on lung health is well established, and smokers are at increased risk of respiratory 
Table 2 COVID-19 misconceptions among the participants $(n=416)$

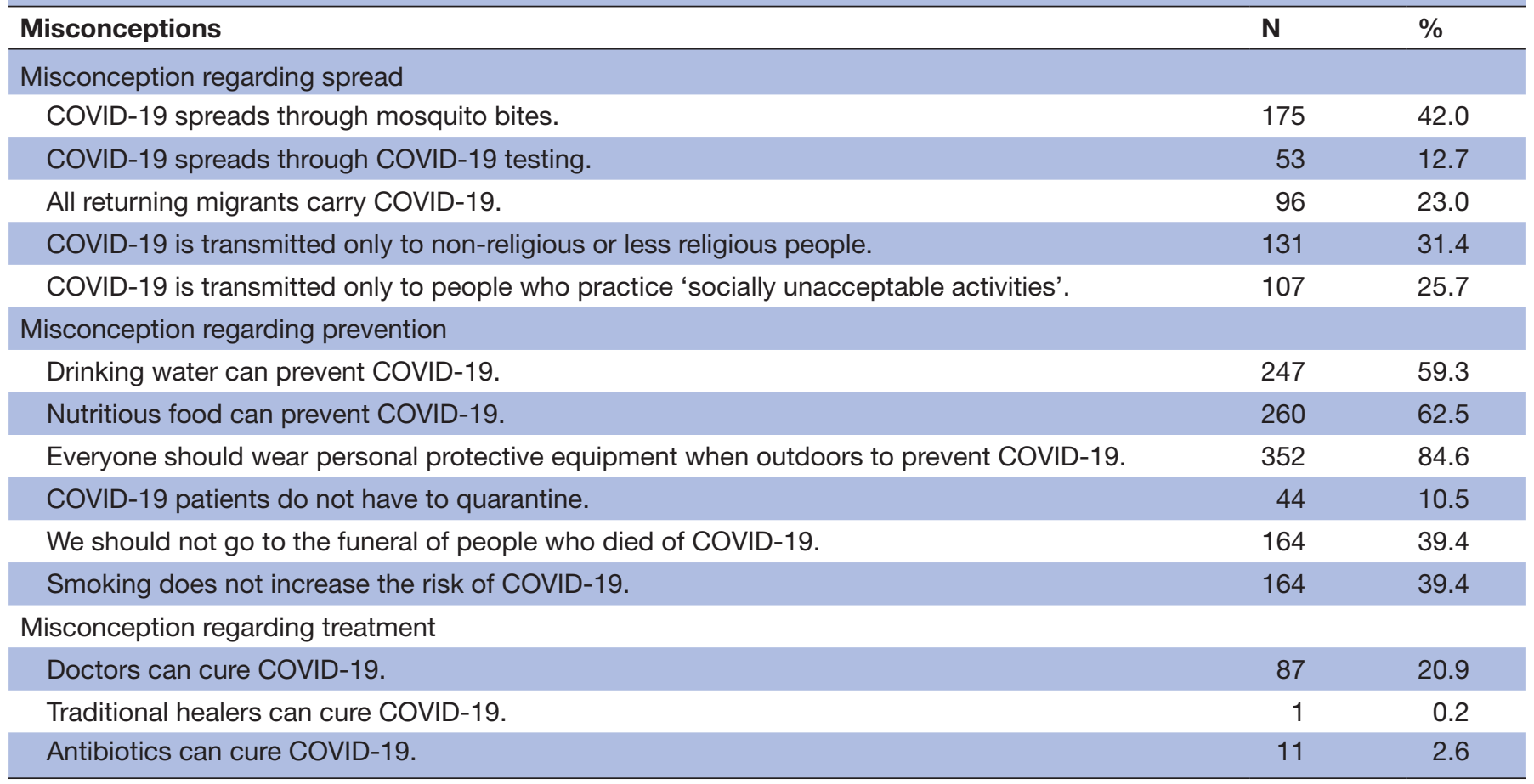

illness. Although it may not influence the likelihood of infection with COVID-19, the emerging evidence suggests that smokers are more likely to develop severe COVID-19 than non-smokers. ${ }^{35}$

Two notables and highly prevalent misconceptions were related to the use of PPE by everyone when outdoors and transmission of infection by returnee migrants. In the beginning, when COVID-19 was limited to China, cases around the world were imported. One of the initial steps taken against COVID-19 by many countries worldwide, including Bangladesh, was to restrict international travel and quarantine travellers on arrival. Such activities were widely reported in the news media and closely paid attention and were the topics of conversation among general Bangladeshis because international migration is very high in Bangladesh, and there was a constant fear of importing the disease. In many instances, people even blamed migrants for bringing COVID-19 into Bangladesh. ${ }^{36}$ So not just among Rohingya refugees, we anticipate the misconceptions that returning migrants carry COVID-19 to be widespread among Bangladeshi people. Another topic that has been even much more widespread in the news outlets is the shortage of essential resources and health services to manage the COVID-19. There are major resource constraints on the Bangladeshi healthcare system, which were widely reported in the media during the pandemic. From the onset of this pandemic, the Bangladeshi government was blamed for shortages of PPE. The importance of PPE in protecting against the infection is indisputable. However, given the muchpublicised shortages, it is possible that participants felt that they needed PPE to protect themselves (and not just the health professionals).
Misinformation is very likely to persist in FDMN camps where internet access is limited, and due to poor health literacy, ${ }^{37}$ the population may not easily distinguish reliable sources of information and depend on less credible sources that promote misconceptions. ${ }^{38}$ To provide accurate information to the FDMNs in camps, volunteers in Cox's Bazar disseminated COVID-19 related information door to door using bicycles and loudspeakers. ${ }^{39}$ Despite these efforts, some misconceptions were highly prevalent among our study population. Two factors-the content of the information and trust in the source of information-may explain our findings. First, the information provided by the dissemination service, which included key COVID-19 information together with general mental health and psychosocial support information, ${ }^{39}$ may not have included the information relevant to the misconceptions covered in our study. In fact, we were glad to note that only a few participants had misconceptions about the treatment of COVID-19, which could be due to these dissemination activities. In terms of prevention, the focus of these dissemination activities was on evidencebased preventive activities such as hand washing, wearing a mask, social distancing and may not have addressed the misconceptions captured in our study. Second, despite making such information available, it is unknown to what extent communities trusted such an external source of information. In times of public health emergencies, distrust of public health officials and their messages have previously been reported among the general population as well as among immigrants and minorities. ${ }^{40}$ For refugee and displaced populations, their specific beliefs, past negative experiences of discrimination, immigration experience and previous encounters and experience with 
Table 3 Factors associated with misconceptions among the participants

\begin{tabular}{|c|c|c|c|}
\hline Characteristics & $\beta$ & $P$ value & $95 \% \mathrm{Cl}$ \\
\hline \multicolumn{4}{|l|}{ Sex } \\
\hline Male & Ref & & \\
\hline Female & -0.27 & 0.169 & -0.66 to 0.12 \\
\hline \multicolumn{4}{|c|}{ Dependent on the family for living } \\
\hline Yes & Ref & & \\
\hline No & 0.30 & 0.150 & -0.11 to 0.72 \\
\hline \multicolumn{4}{|c|}{ Memory or concentration problems } \\
\hline No problem & Ref & & \\
\hline $\begin{array}{l}\text { Low memory or } \\
\text { concentration }\end{array}$ & 0.88 & 0.002 & 0.31 to 1.44 \\
\hline
\end{tabular}

Pre-existing chronic conditions

\begin{tabular}{|c|c|c|c|}
\hline No & Ref & & \\
\hline Yes & 5.88 & $<0.001$ & 2.68 to 12.93 \\
\hline \multicolumn{4}{|c|}{ Radio/TV as the source of COVID-19 information } \\
\hline No & Ref & & \\
\hline Yes & -0.35 & 0.128 & -0.80 to 0.10 \\
\hline \multicolumn{4}{|c|}{ Health worker as the source of COVID-19 information } \\
\hline No & Ref & & \\
\hline Yes & 0.53 & 0.044 & 0.01 to 1.04 \\
\hline \multicolumn{4}{|c|}{$\begin{array}{l}\text { Friends/family/neighbours as the source of COVID- } 19 \\
\text { information }\end{array}$} \\
\hline No & Ref & & \\
\hline Yes & -1.03 & $<0.001$ & -1.55 to -0.52 \\
\hline \multicolumn{4}{|c|}{ Concerned about COVID-19 } \\
\hline Hardly & Ref & & \\
\hline Sometimes/often & 0.28 & 0.193 & -0.14 to 0.70 \\
\hline \multicolumn{4}{|c|}{ Overwhelmed by COVID-19 } \\
\hline Hardly & Ref & & \\
\hline Sometimes/often & -0.96 & $<0.001$ & -1.46 to -0.46 \\
\hline \multicolumn{4}{|c|}{ Frequency of communication during COVID-19 } \\
\hline Same as previous & Ref & & \\
\hline Less than previous & 3.19 & $<0.001$ & 2.67 to 3.70 \\
\hline \multicolumn{4}{|c|}{ Close friends or family members diagnosed with COVID-19 } \\
\hline No & Ref & & \\
\hline Yes & -2.33 & $<0.001$ & -3.43 to -1.22 \\
\hline
\end{tabular}

government or medical institutions may contribute to their trust/distrust. ${ }^{41}$ The same could also explain our most surprising finding that misconceptions were more likely among those who had received COVID-19 information from health workers. In addition, it is also possible that in a resource-constrained healthcare system, healthcare providers themselves may have been inadequately informed and prepared to provide evidence-based information to local communities. When resources need to be prioritised, clinical health professionals are more likely to receive training and resources than frontline community health workers. ${ }^{42}$ So, the community health workers might not be well informed and updated about the evolving knowledge and may not have access to reliable information and training to disseminate positive and authentic information on COVID-19 to the community. If this is true, it highlights the importance of training local social/health workers to counter misconceptions related to COVID-19 among the older FDMNs.

We noted the importance of social networks among our study participants. Misconceptions were lower among those frequently communicating with friends and relatives, receiving COVID-19 information from them, or who had a close friend or family member diagnosed with COVID-19. Historically, Rohingya have a collectivist society with a strong sense of solidarity and mutual support. ${ }^{43}$ Furthermore, the importance of social participation and networking increases with age ${ }^{44}$ so we believe that social networks are critically important for our participants. Specifically, for older Rohingya FDMNs, limited within the camp's physical boundaries and isolated from the global community due to inaccessible technology, younger family members may be an important source of information, both COVID-19 and non-COVID related. Learning from the first-hand experience of a close friend or family member diagnosed with COVID-19 may have been pivotal in reducing our participants' misconceptions. As a COVID-19 case, our participants' social network may have received valid information from humanitarian or health staff that they may have passed on to the community, thereby reducing the misconceptions. As the head of the household or as a close companion, some of our participants may even have had an opportunity to learn how to navigate the health system and use its resources. Thus, they may have gained reliable information to combat misinformation. Language is one of the greatest barriers to access health information among immigrants and refugees. ${ }^{45}$ To overcome that barrier, it is common to train local community members and recruit them as a community health worker. Hence, during the survey, our participants may have identified those community health workers as their family members or relatives or friends and thus misclassified their information source.

Three in 10 participants had a prevalent noncommunicable chronic condition and had higher COVID-19 misconceptions than those without it. Given that those with pre-existing conditions are at greater risk of severe illness and mortality, ${ }^{46}$ it is plausible to assume that they are more likely to panic and strive to find more information about the disease. In an infodemic, rumours and misconceptions are more widespread than facts. Consequently, members of the public may be more susceptible to the spread of misinformation as they may accept any information related to COVID-19 without verifying the source's credibility. This finding is worrisome and has implications for their self-management and adherence to treatment for their chronic conditions as misconceptions preclude adherence to medical treatments and preventive measures. Hence, health workers 
have added responsibilities to fight against misconceptions. Low literacy levels among the Rohingya community might have posed additional challenges to evaluate the information they receive from various sources. ${ }^{47}$

These misconceptions among older Rohingya adults have several implications for public health practice. First, misinformation may cause them to deviate from following public health recommendations. Given that our study participants are one of the most vulnerable population for severe COVID-19 outcomes, ignoring public health measures may lead to very unfavourable health outcomes. Second, in a collectivist society where the household head or the decision maker is the older family member, misconceptions and misinformation among household heads prevent younger family members from accessing healthcare. For example, they may prevent their daughters and daughters-in-law and grandchildren from seeking health services, including future immunisation programmes against the CVOID-19. Third, the ongoing COVID-19 dissemination activities have an opportunity to expand their education to tackle locally prevalent myths specifically.

To the best of our knowledge, this is the first study that systematically explored the level of COVID-19 related misconceptions among the FDMN older adults in Bangladesh. However, the study has certain limitations. First, there is a possibility of selection bias as we conveniently selected a camp and purposively selected the participants from the selected camp in the absence of the listing of older adults. Second, the purposive sampling limits the generalisability of study findings to the entire camp population. Third, although we did a thorough literature review to identify probable misconceptions, yet there are possibilities that we might have missed some potential misconceptions or worded these in a way that may have biased responses (especially regarding the use of traditional medicine for COVID-19).

\section{CONCLUSION}

Older Rohingya adults are a higher at-risk group for COVID-19 transmission, and their risk may be further exacerbated when misconceptions are prevalent. All the relevant organisations closely assisting the management of Rohingya FDMNs in Bangladesh, such as the Government, United National, bilateral agencies and humanitarian non-government organisations, need to prioritise getting more accurate information and educating older Rohingya FDMNs. Failure to provide appropriate information may worsen the spread and impact of the pandemic in the overcrowded camps. Health workers are key sources of health-related information for the refugees. As such, they should be provided with regular training to update their knowledge and decrease misconceptions. It is also very important to provide health literacy intervention as part of infodemic management to address the behaviour at all levels-individual, community, healthcare and humanitarian workers.

\section{Author affiliations}

${ }^{1}$ Department of Health Research, ARCED Foundation, Dhaka, Bangladesh

${ }^{2}$ Centre for Primary Health Care and Equity, University of New South Wales, Sydney, New South Wales, Australia

${ }^{3}$ Department of Sociology and Gerontology and Scripps Gerontology Center, Miami University, Oxford, Ohio, USA

${ }^{4}$ BRAC James P Grant School of Public Health, BRAC University, Dhaka, Dhaka District, Bangladesh

${ }^{5}$ Action Lab, Department of Human-Centred Computing, Faculty of Information Technology, Monash University, Clayton, Victoria, Australia

${ }^{6}$ Department of Health, Society for Health Extension and Development (SHED), Cox's Bazar, Bangladesh

${ }^{7}$ Institute of Nutrition and Food Science, University of Dhaka, Dhaka, Dhaka District, Bangladesh

${ }^{8}$ Office of the Refugee Relief and Repatriation Commissioner (RRRC), Ministry of Disaster Management and Relief, Government of Bangladesh, Cox's Bazar, Bangladesh

Twitter Uday Narayan Yadav @UNYadav_

Acknowledgements We would like to acknowledge the role of Md. Zahirul Islam, Relationship Development Manger, ARCED Foundation, who facilitated smooth data collection for the study.

Contributors SKM, AMA and UNY conceived and contributed to the design of the study. SKM and AMA carried out the data collection and analysis. SKM, AMA, UNY, SG, MBH, MS, SR, ATMRHB and PB contributed in writing the first draft of the manuscript. SG, UNY and MH commented extensively on the draft of the manuscript to finalise it. All authors read and approved the final version of the manuscript.

Funding The authors have not declared a specific grant for this research from any funding agency in the public, commercial or not-for-profit sectors.

Competing interests None declared.

Patient consent for publication Not required.

Ethics approval The institutional review board of the Institute of Health Economics, University of Dhaka, Bangladesh, approved the study protocol (Ref: IHE/2020/1037), and the guidelines of the Declaration of Helsinki were followed in every stage of the study. Informed written consent was sought from the participants (thumb impressions from those who could not read and write) before administering the survey. Participation was voluntary, and participants did not receive any compensation. Written approval was also sought from the Office of the Refugee Relief and Repatriation Commissioner (RRRC) prior to accessing the camps and conducting the survey.

Provenance and peer review Not commissioned; externally peer reviewed.

Data availability statement Data will be available from the corresponding author with a reasonable request.

Supplemental material This content has been supplied by the author(s). It has not been vetted by BMJ Publishing Group Limited (BMJ) and may not have been peer-reviewed. Any opinions or recommendations discussed are solely those of the author(s) and are not endorsed by BMJ. BMJ disclaims all liability and responsibility arising from any reliance placed on the content. Where the content includes any translated material, BMJ does not warrant the accuracy and reliability of the translations (including but not limited to local regulations, clinical guidelines, terminology, drug names and drug dosages), and is not responsible for any error and/or omissions arising from translation and adaptation or otherwise.

Open access This is an open access article distributed in accordance with the Creative Commons Attribution Non Commercial (CC BY-NC 4.0) license, which permits others to distribute, remix, adapt, build upon this work noncommercially, and license their derivative works on different terms, provided the original work is properly cited, appropriate credit is given, any changes made indicated, and the use is non-commercial. See: http://creativecommons.org/ licenses/by-nc/4.0/.

\section{ORCID iDs}

Sabuj Kanti Mistry http://orcid.org/0000-0001-6100-6076

A R M Mehrab Ali http://orcid.org/0000-0001-5442-7147

Uday Narayan Yadav http://orcid.org/0000-0002-6626-1604

Md. Belal Hossain http://orcid.org/0000-0003-4603-863X

Mark Harris http://orcid.org/0000-0002-0705-8913 


\section{REFERENCES}

1 WHO. Who coronavirus disease (COVID-19) Dashboard, 2020. Available: https://covid19.who.int/ [Accessed 07 Dec 2020].

2 Macharia PM, Joseph NK, Okiro EA. A vulnerability index for COVID-19: spatial analysis at the subnational level in Kenya. BMJ Glob Health 2020;5:e003014.

3 Truelove S, Abrahim O, Altare C, et al. The potential impact of COVID-19 in refugee camps in Bangladesh and beyond: a modeling study. PLoS Med 2020;17:e1003144.

4 CDC COVID-19 Response Team. Severe Outcomes Among Patients with Coronavirus Disease 2019 (COVID-19) - United States, February 12-March 16, 2020. MMWR Morb Mortal Wkly Rep 2020;69:343-6.

5 CDC. Coronavirus disease 2019 (COVID-19): older adults, 2020. Available: https://www.cdc.gov/coronavirus/2019-ncov/need-extraprecautions/older-adults.html [Accessed 22 Oct 2020].

6 Refugees International. COVID-19 and the displaced: addressing the threat of the novel coronavirus in humanitarian emergencies, 2020. Available: https://www.refugeesinternational.org/reports/2020/3/29/ covid-19-and-the-displaced-addressing-the-threat-of-the-novelcoronavirus-in-humanitarian-emergencies [Accessed 06 Nov 2020]

7 UNHCR. Coronavirus outbreak, 2020. Available: https://www.unhcr. org/en-us/coronavirus-covid-19.html [Accessed 22 Oct 2020].

8 News BBC. Myanmar Rohingya: what you need to know about the crisis. author, 2020.

9 Prasse-Freeman E. The Rohingya crisis. Anthropology Today 2017;33:1-2

10 MSF. Timeline: a visual history of the Rohingya refugee crisis, 2020 Available: https://www.doctorswithoutborders.org/what-we-do/ news-stories/news/timeline-visual-history-rohingya-refugee-crisis [Accessed 09 Feb 2021].

11 OCHA. Rohingya refugee crisis, 2018. Available: https://www. unocha.org/rohingya-refugee-crisis [Accessed 09 Feb 2021].

12 UNICEF. Rohingya crisis. Available: https://www.unicef.org/ emergencies/rohingya-crisis [Accessed 09 Feb 2021]

13 Homaira N, Islam MS, Haider N. COVID-19 in the Rohingya refugee camps of Bangladesh: challenges and mitigation strategies. Global Biosecurity 2020;1.

14 Kamal A-HM, Huda DMN, Dell DCA, et al. Translational strategies to control and prevent spread of COVID-19 in the Rohiynga refugee camps in Bangladesh. Global Biosecurity 2020;1.

15 UNHCR. Joint Government of Bangladesh - UNHCR Population Factsheet, 2020. Available: file:///C:/Users/z3430797/Downloads/ GoB\%20UNHCR\%20Population\%20Factsheet\%20_\%20March\% 2015.pdf [Accessed 22 Oct 2020].

16 Islam MM, Yunus MY. Rohingya refugees at high risk of COVID-19 in Bangladesh. Lancet Glob Health 2020;8:e993-4.

17 Limon MTI, Jubayer MF, Ahmed MU, et al. Rohingya refugees and coronavirus Disease-2019: addressing possible jeopardy from the perspective of Bangladesh. Asia Pac J Public Health 2020;32:529-30.

18 Alam N, Kenny B, Maguire JE, et al. Field epidemiology in action: an Australian perspective of epidemic response to the Rohingya health emergencies in Cox's Bazar, Bangladesh. Global Biosecurity 2019;1:119.

19 WHO. Bangladesh: Rohingya refugee crisis 2017-2018, 2018. Available: http://www.searo.who.int/mediacentre/emergencies/ bangladesh-myanmar/public-healthsituation-analysis-may-2018.pdf

20 Joarder T, Sutradhar I, Hasan MI, et al. A record review on the health status of Rohingya refugees in Bangladesh. Cureus 2020;12:e9753.

21 Future Direction International. Food security and the Rohingya refugee crisis, 2018. Available: https://www.futuredirections.org. au/publication/food-security-and-the-rohingya-refugee-crisis/ [Accessed 22 Oct 2020].

22 WHO. Rohingya Crisis: Situation Report \#2, 2021. Available: https://cdn.who.int/media/docs/default-source/searo/bangladesh/ bangladesh-rohingya-crisis-pdf-reports/sitreps/2021/who-cxbsituation-report-2.pdf?sfvrsn=e984927c_7 [Accessed 09 Feb 2021].

23 Reuters. Fear stops Rohingya getting tested as virus hits refugee camps, 2020. Available: https://www.reuters.com/article/us-healthcoronavirus-rohingya-refugees/fear-stops-rohingya-getting-testedas-virus-hits-refugee-camps-idUSKBN23C1GV [Accessed 22 Oct 2020].

24 Longino A. International Journal of environmental research and public health. Wilderness Environ Med 2015;26:99.

25 Mian A, Khan S. Medical education during pandemics: a UK perspective. BMC Med 2020;18:1-2.
26 Human Rights Watch. Bangladesh: Internet blackout on Rohingya refugees, 2019. Available: https://www.hrw.org/news/2019/09/13/ bangladesh-internet-blackout-rohingya-refugees\#: :text=On\% 20September\%209\%2C\%202019\%2C\%20the,shut\%20down\% 20 since $\% 20$ September\%2010 [Accessed 06 Nov 2020].

27 Amnest International. Bangladesh: COVID-19 response flaws put older Rohingya refugees in imminent danger, 2020. Available: https:// www.amnesty.org.au/bangladesh-covid-19-response-flaws-putolder-rohingya-refugees-in-imminent-danger/ [Accessed 22 Oct 2020].

28 Reuters. In the world's largest refugee camp, a female cleric tackles coronavirus myths, 2020. Available: https://news.trust.org/item/ 20200825161334-h13km/ [Accessed 22 Oct 2020].

29 WHO. Coronavirus disease (COVID-19) advice for the public: Mythbusters, 2020. Available: https://www.who.int/emergencies/ diseases/novel-coronavirus-2019/advice-for-public/myth-busters [Accessed 22 Oct 2020].

30 Carlson CJ, Gomez ACR, Bansal S, et al. Misconceptions about weather and seasonality must not misguide COVID-19 response. Nat Commun 2020:11:1-4.

31 Kasozi KI, MacLeod E, Ssempijja F, et al. Misconceptions on COVID-19 risk among Ugandan men: results from a rapid exploratory survey, April 2020. Front Public Health 2020;8:416.

32 Sahoo S, Padhy SK, Ipsita J, et al. Demystifying the myths about COVID-19 infection and its societal importance. Asian J Psychiatr 2020;54:102244.

33 businesswire. Do mosquitoes and ticks transmit COVID-19? experts say no, 2020. Available: https://www.businesswire.com/news/home/ 20200413005267/en/Do-Mosquitoes-and-Ticks-Transmit-COVID-19Experts-Say-No [Accessed 22 Oct 2020]

34 Thomas R, Greenwood H, Michaleff ZA, et al. Examining Australian's beliefs, misconceptions, and sources of information for COVID-19: A national online survey. medRxiv 2020

35 WHO. Smoking and COVID-19: scientific brief, 2020. Available: file:///C:/Users/z3430797/Downloads/WHO-2019-nCoV-Sci_BriefSmoking-2020.2-eng.pdf [Accessed 22 Oct 2020].

36 Bodrud-Doza M, Shammi M, Bahlman L, et al. Psychosocial and socio-economic crisis in Bangladesh due to COVID-19 pandemic: a perception-based assessment. Front Public Health 2020;8:341.

37 Bhatia A, Mahmud A, Fuller A, et al. The Rohingya in COX's Bazar: when the Stateless seek refuge. Health Hum Rights 2018;20:105.

38 camh. Stigma and prejudice: how to combat the rise in discrimination that has been sparked by the COVID-19 pandemic, 2020. Available: https://www.camh.ca/en/health-info/mental-health-and-covid-19/ stigma-and-prejudice [Accessed 22 Oct 2020].

39 UN. Battling COVID-19 misinformation hands-on, 2020. Available: https://www.un.org/en/battling-covid-19-misinformation-hands [Accessed 22 Oct 2020]

40 Earnshaw VA, Bogart LM, Klompas M, et al. Medical mistrust in the context of Ebola: implications for intended care-seeking and quarantine policy support in the United States. $J$ Health Psychol 2019;24:219-28.

41 Truman Bl, Tinker T, Vaughan E, et al. Pandemic influenza preparedness and response among immigrants and refugees 2009;99:S278-86.

42 Ballard M, Bancroft E, Nesbit J, et al. Prioritising the role of community health workers in the COVID-19 response. BMJ Glob Health 2020;5:e002550.

43 Tay AK, Islam R, Riley A. Culture, context and mental health of Rohingya refugees: a review for staff in mental health and psychosocial support programmes for Rohingya refugees. Geneva: United Nations High Commissioner for Refugees (UNHCR), 2018.

44 Dawson-Townsend K. Social participation patterns and their associations with health and well-being for older adults. SSM Popul Health 2019;8:100424.

45 Chuah FLH, Tan ST, Yeo J, et al. The health needs and access barriers among refugees and asylum-seekers in Malaysia: a qualitative study. Int J Equity Health 2018;17:120.

46 CDC. Coronavirus disease 2019 (COVID-19): people with certain medical conditions, 2020. Available: https://www.cdc.gov/ coronavirus/2019-ncov/need-extra-precautions/people-withmedical-conditions.html [Accessed 22 Oct 2020].

47 WHO. WHO \& Partners Enhance Support to COVID-19 response in Rohingya Camps in Cox's Bazar, 2020. Available: https://www.who. int/southeastasia/news/feature-stories/detail/who-partners-enhancesupport-to-covid-19-response-in-rohingya-camps-in-coxs-bazar [Accessed 22 Oct 2020]. 